\title{
Are the argon metastables important in high power impulse magnetron sputtering discharges?
}

\author{
J. T. Gudmundsson, D. Lundin, G. D. Stancu, Nils Brenning and T. M. Minea
}

\section{Linköping University Post Print}

\section{Tweet}

N.B.: When citing this work, cite the original article.

Original Publication:

J. T. Gudmundsson, D. Lundin, G. D. Stancu, Nils Brenning and T. M. Minea, Are the argon metastables important in high power impulse magnetron sputtering discharges?, 2015, Physics of Plasmas, (22), 11, 113508.

http://dx.doi.org/10.1063/1.4935402

Copyright: American Institute of Physics (AIP)

http://www.aip.org/

Postprint available at: Linköping University Electronic Press

http://urn.kb.se/resolve?urn=urn:nbn:se:liu:diva-123815 


\section{AIP $\left.\right|_{\text {Physics of }}$

\section{Are the argon metastables important in high power impulse magnetron sputtering}

discharges?

J. T. Gudmundsson, D. Lundin, G. D. Stancu, N. Brenning, and T. M. Minea

Citation: Physics of Plasmas 22, 113508 (2015); doi: 10.1063/1.4935402

View online: http://dx.doi.org/10.1063/1.4935402

View Table of Contents: http://scitation.aip.org/content/aip/journal/pop/22/11?ver=pdfcov

Published by the AIP Publishing

\section{Articles you may be interested in}

Particle visualization in high-power impulse magnetron sputtering. II. Absolute density dynamics

J. Appl. Phys. 117, 163303 (2015); 10.1063/1.4919007

Rarefaction windows in a high-power impulse magnetron sputtering plasma

J. Appl. Phys. 114, 113302 (2013); 10.1063/1.4821514

Time-resolved temperature study in a high-power impulse magnetron sputtering discharge

J. Appl. Phys. 114, 013301 (2013); 10.1063/1.4812579

High power impulse magnetron sputtering: Current-voltage-time characteristics indicate the onset of sustained self-sputtering

J. Appl. Phys. 102, 113303 (2007); 10.1063/1.2817812

Ionization of sputtered material in a planar magnetron discharge

J. Vac. Sci. Technol. A 18, 2897 (2000); 10.1116/1.1312370

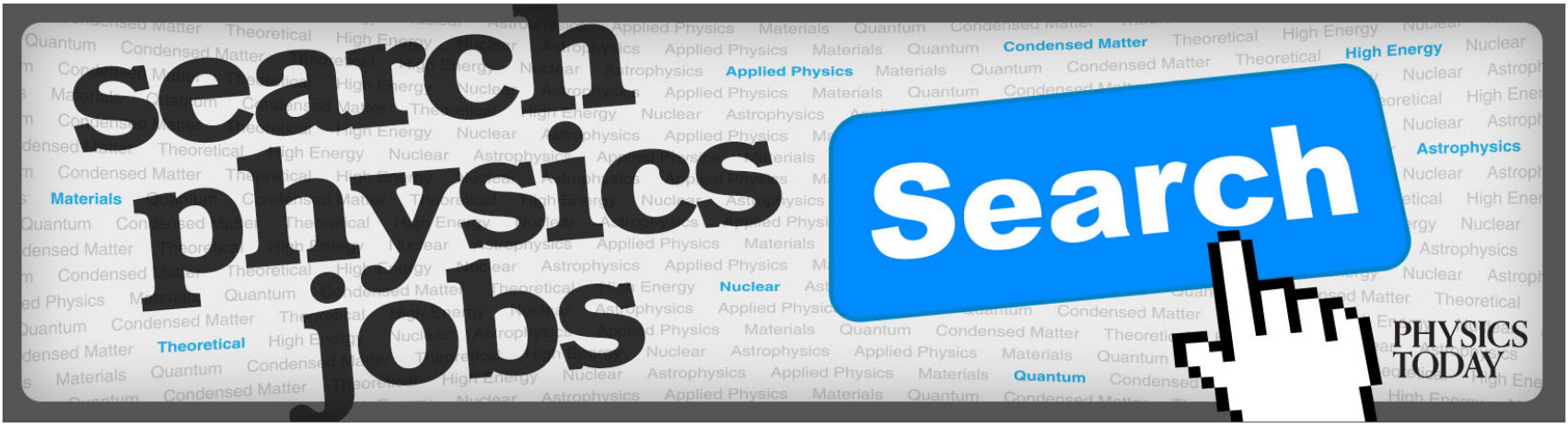




\title{
Are the argon metastables important in high power impulse magnetron sputtering discharges?
}

\author{
J. T. Gudmundsson, ${ }^{1,2, a)}$ D. Lundin, ${ }^{3}$ G. D. Stancu, ${ }^{4,5}$ N. Brenning,,${ }^{1,6}$ and T. M. Minea ${ }^{3}$ \\ ${ }^{1}$ Department of Space and Plasma Physics, School of Electrical Engineering, KTH Royal Institute \\ of Technology, SE-100 44 Stockholm, Sweden \\ ${ }^{2}$ Science Institute, University of Iceland, Dunhaga 3, IS-107 Reykjavik, Iceland \\ ${ }^{3}$ Laboratoire de Physique des Gaz et Plasmas - LPGP, UMR 8578 CNRS, Université Paris-Sud, \\ 91405 Orsay Cedex, France \\ ${ }^{4}$ CentraleSupélec, Grande Voie des Vignes, 92295 Chatenay-Malabry Cedex, France \\ ${ }^{5}$ CNRS, UPR 288 Laboratoire EM2C, Grande Voie des Vignes, 92295 Chatenay-Malabry Cedex, France \\ ${ }^{6}$ Plasma and Coatings Physics Division, IFM-Materials Physics, Linköping University, SE-581 83 Linköping, \\ Sweden
}

(Received 16 June 2015; accepted 27 October 2015; published online 11 November 2015)

We use an ionization region model to explore the ionization processes in the high power impulse magnetron sputtering (HiPIMS) discharge in argon with a titanium target. In conventional dc magnetron sputtering (dcMS), stepwise ionization can be an important route for ionization of the argon gas. However, in the HiPIMS discharge stepwise ionization is found to be negligible during the breakdown phase of the HiPIMS pulse and becomes significant (but never dominating) only later in the pulse. For the sputtered species, Penning ionization can be a significant ionization mechanism in the dcMS discharges, while in the HiPIMS discharge Penning ionization is always negligible as compared to electron impact ionization. The main reasons for these differences are a higher plasma density in the HiPIMS discharge, and a higher electron temperature. Furthermore, we explore the ionization fraction and the ionized flux fraction of the sputtered vapor and compare with recent experimental work. (C) 2015 AIP Publishing LLC. [http://dx.doi.org/10.1063/1.4935402]

\section{INTRODUCTION}

The high power impulse magnetron sputtering (HiPIMS) discharge is an ionized physical vapor deposition (IPVD) technique that has attracted much interest during the last decade. ${ }^{1}$ The HiPIMS discharge was derived from studies of high power pulsing of a discharge created between plane parallel electrodes ${ }^{2}$ and later in a transverse magnetic field. ${ }^{3}$ In HiPIMS, high power is applied to the magnetron target in short $(10-500 \mu \mathrm{s})$ unipolar pulses at low duty cycle and low repetition frequency $(50-5000 \mathrm{~Hz})$ while keeping the average power about 2 orders of magnitude lower than the peak power. ${ }^{1}$ This results in a high plasma density, and very high ionization fraction of the sputtered vapor. The high ionization fraction improves the control of the film growth as it is possible to control the energy and direction of the deposition species, which is a significant advantage over conventional dc magnetron sputtering (dcMS) where the sputtered vapor consists mainly of neutral species.

To study the ionization as well as other key features of the HiPIMS discharge, an ionization region model (IRM) ${ }^{4}$ was developed to capture the main features of the plasma behavior during an HiPIMS pulse and the afterglow. The main characteristic of the model is that an ionization region (IR) is defined next to the race track formed in the sputtering target, in which the temporal behavior of the volume averaged density of all species is determined for a given applied power and pressure. This type of a global model provides a

\footnotetext{
a)tumi@hi.is
}

flexible tool to explore the ionization processes, the temporal variations of the ionized fractions of the working gas and the sputtered vapor, and the electron density and temperature. The model has previously been applied to study gas rarefaction and refill processes, ${ }^{4,5}$ the properties of both short ${ }^{4}$ and long pulses, ${ }^{5}$ the loss in deposition rate,${ }^{6}$ the electron heating mechanism, ${ }^{7}$ and the onset of self sputtering, ${ }^{8}$ for a discharge with $\mathrm{Al}$ target, and the temporal behavior of the argon metastables for a discharge with Ti target. ${ }^{9}$ For the latter study, a version of the IRM was developed that included detailed treatment of the kinetics of the metastable states of the argon atom $\mathrm{Ar}^{\mathrm{m}}$. This version will from now on be referred to as m-IRM. The m-IRM was demonstrated to accurately follow the time development of the metastable density and the results were validated against measurements taken by tunable diode laser absorption spectroscopy (TD-LAS). ${ }^{10}$

For the purpose of investigating ionization processes, Kudryavtsev and Skrebov ${ }^{11}$ developed a model to study the initial stages of the plasma discharge and the build up of electron density. They recognized two possible cases of the growth of electron density in the plasma. In the first case, the primary role is played by stepwise ionization via a metastable state. In this case, the growth of the electron density at an initial stage is very slow, due to the fact that first there is an accumulation of metastable atoms. Subsequently, when a certain density of metastable atoms is reached, the ionization from the metastable state becomes predominant, causing an abrupt increase in the electron density to the value in the quasi-stationary regime. In the second case, the mechanism determining the increase in the electron and ion density is 
dominated by direct ionization of argon from the ground state. The growth of the electron density in this case occurs without a marked jump in the electron density. For a magnetron sputtering discharge in argon at 1.33-133 Pa, magnetic field density up to $0.3 \mathrm{~T}$, and pulse voltage amplitude up to $3 \mathrm{kV}$, the second mechanism is the one realized in practice. ${ }^{12}$ Recent experimental studies of the HiPIMS discharge in argon with a titanium target include the recording of the temporal density variation of $\mathrm{Ti}, \mathrm{Ti}^{+}, \mathrm{Ar}$, and $\mathrm{Ar}^{+}$along with metastable states using resonant absorption spectroscopy ${ }^{13}$ and 2D mapping of the $\mathrm{Ti}, \mathrm{Ti}^{+}$, and $\mathrm{Ar}^{\mathrm{m}}$ using laser induced fluorescence (LIF), ${ }^{14}$ determination of the electron density and electron temperature, ${ }^{15,16}$ and ionized flux fraction, ${ }^{16-19}$ and determination of the titanium ionization fraction..$^{13,20}$ Here, we study the role of the argon metastables using the m-IRM for HiPIMS discharges, in particular, how much of the ionization goes through stepwise ionization and what is the role of Penning ionization for the ionization of the sputtered species. We will also discuss the temporal behavior of the various species as well as the ionization fraction and the ionized flux fraction for titanium and argon and compare with the experimental findings.

\section{THE IONIZATION REGION MODEL}

In the magnetron sputtering discharge, it is well known that a high density brightly glowing torus shaped plasma hovers next to the target surface and extends a few $\mathrm{cm}$ from the cathode target and is embedded in a lower density plasma bulk. Based on this, the IR is defined as an annular cylinder with outer radii $r_{\mathrm{c} 2}$ and inner radii $r_{\mathrm{c} 1}$ which extends from $z_{1}$ to $z_{2}$ axially away from the target. Geometrical effects are included indirectly as loss and gain rates across the boundaries of this annular cylinder to the target and the bulk plasma. ${ }^{4}$ The temporal development is defined by a set of ordinary differential equations giving the first time derivatives of the electron energy and the particle densities for all the species. The electron density is found assuming quasineutrality of the plasma. The model assumes only volumeaveraged values over the whole IR volume for the electron, ion, and neutral densities. For simplification, we assume a Maxwellian electron energy distribution function (EEDF) while calculating the rate coefficients but we have by separate calculations verified that the $\mathrm{Ar}^{\mathrm{m}}$ density is only marginally changed if the EEDF contains $0.01 \%$ hot $(100-500 \mathrm{~V})$ electrons which is a typical fraction in a pulse. ${ }^{21}$

The main reactions we will address in this work are the electron impact ionization of titanium,

$$
\mathrm{e}+\mathrm{Ti} \rightarrow \mathrm{Ti}^{+}+2 \mathrm{e}
$$

and the set of reactions shown in Fig. 1. The most important of these is excitation from the ground state argon atom to the metastable levels denoted by $\mathrm{Ar}^{\mathrm{m}}$

$$
\mathrm{e}+\mathrm{Ar} \rightarrow \mathrm{Ar}^{\mathrm{m}}+\mathrm{e},
$$

where we assume that $\mathrm{Ar}^{\mathrm{m}}$ represents both the metastable levels in the $3 \mathrm{~s}^{2} 3 \mathrm{p}^{5} 4 \mathrm{~s}$ shell $\left({ }^{3} \mathrm{P}_{0}\right.$ and $\left.{ }^{3} \mathrm{P}_{2}\right)$ at energies 11.72 and $11.55 \mathrm{eV}$, respectively. The rate coefficient we use for

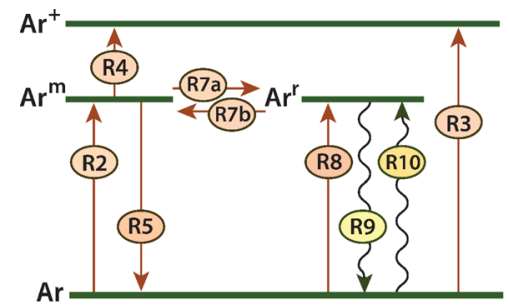

(a)

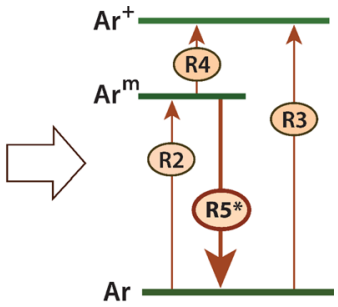

(b)
FIG. 1. An energy level diagram for the main processes involving the argon metastable $\mathrm{Ar}^{\mathrm{m}}$ levels. Electron induced reactions are marked by solid arrows and radiative transitions by curvy lines. (a) The complete reaction scheme, including de-excitation from $\mathrm{Ar}^{\mathrm{m}}$ to the ground state via the resonant $\mathrm{Ar}^{\mathrm{r}}$ levels. (b) A simplified reaction scheme in which the quenching reaction (R5), and the $\mathrm{Ar}^{\mathrm{r}}$ reactions $\mathrm{R} 7 \mathrm{a}$ to $\mathrm{R} 10$, are combined to an effective de-excitation reaction $\mathrm{R} 5^{*}$.

reaction (R2) also takes into account the higher laying $4 p$ levels that cascade to the metastable levels $\mathrm{Ar}^{\mathrm{m}}$ as discussed by Stancu et $a l .{ }^{9}$ We include direct ionization of argon by electron impact from the ground state

$$
\mathrm{e}+\mathrm{Ar} \rightarrow \mathrm{Ar}^{+}+2 \mathrm{e}
$$

and ionization from the metastable levels $\mathrm{Ar}^{\mathrm{m}}$

$$
\mathrm{e}+\mathrm{Ar}^{\mathrm{m}} \rightarrow \mathrm{Ar}^{+}+2 \mathrm{e} .
$$

Transitions from $\mathrm{Ar}^{\mathrm{m}}$ to the ground state can go by two routes as illustrated in Fig. 1. The first route is by electron impact quenching (superelastic) collisions

$$
\mathrm{e}+\mathrm{Ar}^{\mathrm{m}} \rightarrow \mathrm{Ar}+\mathrm{e} .
$$

The second route is de-excitation from $\mathrm{Ar}^{\mathrm{m}}$ by coupling to the resonant levels $\mathrm{Ar}^{\mathrm{r}}$. The involved reactions (not written out here) are numbered R7a to R10 in Fig. 1(a). The reactions considered in the complete reaction scheme are listed in Table I. Electron-impact induced transitions between the $\mathrm{Ar}^{\mathrm{m}}$ and $\mathrm{Ar}^{\mathrm{r}}$ levels (reactions R7a and R7b) will, at high enough plasma density, populate these levels according to their statistical weights. The two resonant levels have very large radiative rates (reaction R9) to the ground state, $5.1 \times 10^{8} \mathrm{~Hz}$ and $1.2 \times 10^{8}$ $\mathrm{Hz}$, respectively. This opens up an additional loss channel from $\mathrm{Ar}^{\mathrm{m}}$ to the ground state (reactions $\mathrm{R} 7 \mathrm{a}+\mathrm{R} 9$ ). The

TABLE I. The reactions considered in the more detailed model shown in Figure 1(a).

\begin{tabular}{lcc}
\hline \hline Reactions & Nos. & Process \\
\hline $\mathrm{e}+\mathrm{Ti} \rightarrow \mathrm{Ti}^{+}+2 \mathrm{e}$ & $\mathrm{R} 1$ & Titanium ionization \\
$\mathrm{e}+\mathrm{Ar} \rightarrow \mathrm{Ar}^{\mathrm{m}}+\mathrm{e}$ & $\mathrm{R} 2$ & Metastable excitation \\
$\mathrm{e}+\mathrm{Ar} \rightarrow \mathrm{Ar}^{+}+2 \mathrm{e}$ & $\mathrm{R} 3$ & Argon ionization \\
$\mathrm{e}+\mathrm{Ar}^{\mathrm{m}} \rightarrow \mathrm{Ar}^{+}+2 \mathrm{e}$ & $\mathrm{R} 4$ & Ionization of metastable \\
$\mathrm{e}+\mathrm{Ar}^{\mathrm{m}} \rightarrow \mathrm{Ar}+2 \mathrm{e}$ & $\mathrm{R} 5$ & Electron quenching of metastable \\
$\mathrm{Ar}^{\mathrm{m}}+\mathrm{Ti} \rightarrow \mathrm{Ar}+\mathrm{Ti}^{+}+\mathrm{e}$ & $\mathrm{R} 6$ & Penning ionization \\
$\mathrm{e}+\mathrm{Ar}^{\mathrm{m}} \rightarrow \mathrm{Ar}^{\mathrm{r}}+\mathrm{e}$ & $\mathrm{R} 7 \mathrm{a}$ & Metastable to resonant level \\
$\mathrm{e}+\mathrm{Ar}^{\mathrm{r}} \rightarrow \mathrm{Ar}^{\mathrm{m}}+\mathrm{e}$ & $\mathrm{R} 7 \mathrm{~b}$ & Resonant to metastable level \\
$\mathrm{e}+\mathrm{Ar} \rightarrow \mathrm{Ar}^{\mathrm{r}}+\mathrm{e}$ & $\mathrm{R} 8$ & Resonant level excitation \\
$\mathrm{Ar} \rightarrow \mathrm{Ar}+h \nu$ & $\mathrm{R} 9$ & Resonant state decay \\
$\mathrm{Ar}+h \nu \rightarrow \mathrm{Ar}^{\mathrm{r}}$ & $\mathrm{R} 10$ & Resonant self absorption \\
\hline \hline
\end{tabular}


effectiveness of this channel, however, is reduced by the absorption of the resonant radiation (reaction R10) which re-populates the $\operatorname{Ar}^{\mathrm{r}}$ levels. For typical pressures in magnetron discharges, the resonant radiation has escape factors in the range of $10^{-4}-10^{-2}$ which partially, but not totally, blocks this loss channel. The net effect of reactions R7a to R10 in Fig. 1(a) thus depends both on the plasma density (through reactions $\mathrm{R} 7 \mathrm{a}, \mathrm{R} 7 \mathrm{~b}$, and $\mathrm{R} 8$ ) and the argon gas density (through reaction $\mathrm{R} 10$ ), and must be individually modeled for each discharge for accurate results. The extreme cases of zero and complete level mixing, and of zero and complete imprisonment, were, however, analyzed by Stancu et al. ${ }^{9}$ Based on their results we replace, in our $\mathrm{m}$-IRM runs, the quenching reaction (R5) by an effective de-excitation reaction $\mathrm{R} 5^{*}$ as shown in Fig. 1(b). The rate coefficient for $\mathrm{R} 5^{*}$ lies in the range from $k_{\mathrm{R} 5^{*}}=k_{\mathrm{R} 5}$ for complete imprisonment to $k_{\mathrm{R} 5^{*}}=k_{\mathrm{R} 5}+k_{\mathrm{R} 7 \mathrm{a}}$, for zero imprisonment. These limits also hold, as extreme values, independent of the degree of $\operatorname{Ar}^{\mathrm{m}}-\mathrm{Ar}^{\mathrm{r}}$ level mixing. We will herein assume the mean value of these extremes $k_{\mathrm{R} 5^{*}}=\left(k_{\mathrm{R} 5}+0.5 \times k_{\mathrm{R} 7 \mathrm{a}}\right)$, and use the simplified level diagram of Fig. 1(b) to illustrate the results. We also include Penning ionization of $\mathrm{Ti}$

$$
\mathrm{Ar}^{\mathrm{m}}+\mathrm{Ti} \rightarrow \mathrm{Ar}+\mathrm{Ti}^{+}+\mathrm{e}
$$

a process with a relative importance that depends very much on the plasma density. The rate coefficients used in the model calculations are discussed and evaluated by Stancu et al. ${ }^{9}$

The m-IRM follows the time development in the discharge volume by solving the coupled differential equations for the (volume averaged) densities of the various species. Of special interest, here is the rate equation for the metastable density

$$
\begin{aligned}
\frac{\mathrm{d} n_{\mathrm{Ar}}}{\mathrm{d} t}= & n_{\mathrm{Ar}} n_{\mathrm{e}} k_{\mathrm{R} 2}-n_{\mathrm{Ar}}\left[n_{\mathrm{e}}\left(k_{\mathrm{R} 4}+k_{\mathrm{R} 5}^{*}\right)+n_{\mathrm{Ti}} k_{\mathrm{R} 6}\right] \\
& -u_{z, \mathrm{Ar}} \frac{\mathrm{d} n_{\mathrm{Ar}}{ }^{\mathrm{m}}}{\mathrm{d} z}
\end{aligned}
$$

where the indices on the rate coefficients correspond to the reaction numbers above and the mean rate has been used. Here, $n_{\mathrm{Ar}}$ is the metastable atom density, $n_{\mathrm{Ar}}$ is the density of argon atoms in the ground state, $n_{\mathrm{Ti}}$ is the titanium atom density, and $n_{\mathrm{e}}$ is the electron density. The generic last term in Eq. (1) represents diffusion (which is calculated as described in Raadu et l $^{4}{ }^{4}$ ) and $u_{z, A r^{\mathrm{m}}}$ is a velocity due to diffusional outflow (or refill) of $\mathrm{Ar}^{\mathrm{m}}$. A term corresponding to sputter wind kick-out (see Raadu et ll. $^{4}$ ) is negligible for the metastable level.

\section{RESULTS AND DISCUSSION}

We will focus on two dimensionless ratios that reflect two roles which the metastable level can play in the discharge. One ratio is the fraction of Penning ionization of the sputtered target material,

$$
\frac{R_{\text {Penning,iz }}}{\sum_{i} R_{\mathrm{Ti}, \mathrm{iz}, i}}=\frac{\text { rate of Penning ionization to create } \mathrm{Ti}^{+}}{\text {total rate for the creation of } \mathrm{Ti}^{+}} .
$$

The other ratio is the fraction of stepwise ionization (through the metastable states) of the argon working gas

$$
\frac{R_{\text {stepwise, iz }}}{\sum_{i} R_{\mathrm{Ar}, \mathrm{iz}, i}}=\frac{\text { rate of stepwise ionization through } \mathrm{Ar}^{\mathrm{m}}}{\text { total rate for the creation of } \mathrm{Ar}^{+}} .
$$

A case of special interest is when the metastable population is at equilibrium, and when also convection across the boundaries of the studied volume can be neglected. Under these two conditions, the fraction of the total ionization that goes through the metastable level is independent of $n_{\mathrm{e}}$, and can be directly obtained from the involved rate coefficients and depends only on the electron temperature $T_{\mathrm{e}}$

$$
\left(\frac{R_{\text {stepwise }, \mathrm{iz}}}{\sum_{i} R_{\mathrm{Ar}, \mathrm{iz}, i}}\right)_{\mathrm{eq}}=\frac{k_{\mathrm{R} 2} k_{\mathrm{R} 4}}{k_{\mathrm{R} 4}+k_{\mathrm{R} 5^{*}}} /\left(k_{\mathrm{R} 3}+\frac{k_{\mathrm{R} 2} k_{\mathrm{R} 4}}{k_{\mathrm{R} 4}+k_{\mathrm{R} 5^{*}}}\right) .
$$

This expression has been evaluated as a function of $T_{\mathrm{e}}$ and the result is shown as a solid (red) line in Fig. 2. The dashed (blue and green) curves represent the extreme cases of zero and complete imprisonment, and the thin dashed dotted lines show the results when $0.01 \%, 0.1 \%$, and $1 \%$ of the electrons are assumed to be hot $(400 \mathrm{~V})$.

In real discharges, there are both convective terms (sputter wind kick-out and diffusion) and, in HiPIMS pulses, there are in the breakdown phase large departures from equilibrium. We therefore use the m-IRM, which includes these effects, to explore the HiPIMS discharges. The IRM is a semi-empirical model in the sense that it uses a measured discharge current waveform as a main input parameter, as described in detail elsewhere. ${ }^{9}$

In the present work, we investigate experimentally recorded $200 \mu \mathrm{s}$ long pulses with $0.5 \mathrm{~A}, 40 \mathrm{~A}$, and $70 \mathrm{~A}$ peak current, corresponding to an average peak current density over the cathode surface of $0.006,0.7$ (average power of $100 \mathrm{~W}$ ), and $0.9 \mathrm{~A} / \mathrm{cm}^{2}$, and a gas pressure of $1.33 \mathrm{~Pa}$. The target was a titanium disc of $10 \mathrm{~cm}$ diameter and the pulse

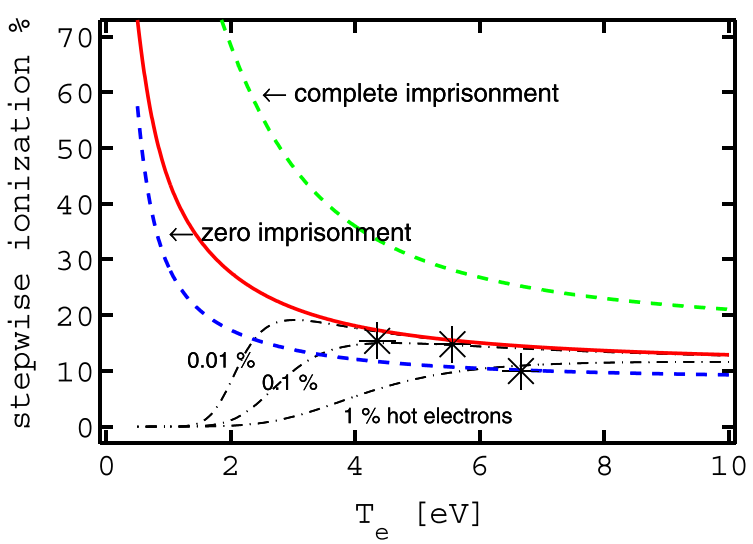

FIG. 2. The relative importance of stepwise ionization of Ar via the metastable state in equilibrium and without convections from Eq. (4), the thick solid (red) line shows the result for the effective average $k_{\mathrm{R} 5^{*}}=k_{\mathrm{R} 5}+0.5 \times k_{\mathrm{R} 7 \mathrm{a}}$, and the thick dashed lines show the extremes $k_{\mathrm{R} 5^{*}}=k_{\mathrm{R} 5}$ (complete imprisonment (green)) and $k_{\mathrm{R} 5^{*}}=k_{\mathrm{R} 5}+k_{\mathrm{R} 7 \mathrm{a}}$ (zero imprisonment (blue)) assuming Maxwellian EEDF. The dashed dotted lines show the results when $0.01 \%$, $0.1 \%$, and $1 \%$ of the electrons are assumed to be hot $(400 \mathrm{~V})$. The $*$ symbol shows the results of the m-IRM calculation for HiPIMS at time $t_{2}$ in Figure 3 for $0.5 \mathrm{~A}, 40 \mathrm{~A}$, and $70 \mathrm{~A}$ peak current. 
repetition frequency was $50 \mathrm{~Hz} .{ }^{9}$ The key parameters for the three cases are listed in Table II. The 0.5 A peak current case is included as the current is roughly two orders of magnitude lower than the other two cases and thus is dcMS like. The $0.5 \mathrm{~A}$ peak current case only reaches electron densities expected in dcMS while the 40 and $70 \mathrm{~A}$ cases give electron densities typical for a HiPIMS discharge. The parameter $\beta$ listed in Table II is the probability that an ionized species of the sputtered vapor returns to the target and is a fitting parameter in the model. ${ }^{6}$ We note that $\beta$ is small $(15 \%)$ for the $0.5 \mathrm{~A}$ peak current case, and it increases with increasing peak current and over $50 \%$ of the ions of the sputtered vapor return to the target for the $70 \mathrm{~A}$ peak current case. Figure 3 shows the temporal variation of the electron temperature $T_{\mathrm{e}}(t)$, and the relative weights of the two reaction paths during the pulse for the three cases explored. The rise with time up to $25 \mu$ s is associated with the time it takes to build up an equilibrium metastable population. ${ }^{9}$ Particularly during the early breakdown phase (the mark $t_{1}=10 \mu$ s in Fig. 3) stepwise ionization through the metastable level plays only a minor role $(0.3 \%-7 \%$ at $1.33 \mathrm{~Pa})$. A flow chart illustration for the $40 \mathrm{~A}$ peak current case is given in Fig. 4(a), with the widths of the arrows taken at the time $t_{1}$ in the simulation run. At this time, the electron density is $3.4 \times 10^{17} \mathrm{~m}^{-3}$. Stepwise ionization via the metastable state plays, at most, a marginal role in the ignition of this HiPIMS pulse. After $25 \mu \mathrm{s}$, the metastable density is close to the equilibrium population with respect to the ground state. A flow chart illustration of this case at $150 \mu \mathrm{s}$ is shown in Fig. 4(b). Here, the contribution from stepwise ionization of argon is $15 \%$, significant but not dominating. For $0.5 \mathrm{~A}$ peak current, stepwise ionization contributes roughly $10 \%$ (Fig. 3(a)) but for $70 \mathrm{~A}$ peak current it contributes 15\% (Fig. 3(c)), $150 \mu$ s into the pulse. These values from the m-IRM run have been marked onto Fig. 2 with a star and deviate only slightly from the simple estimate at equilibrium (Eq. (4)).

In steady state, and neglecting the small diffusion and kick-out terms, the rate equation for the titanium ions (not shown) gives

$$
\frac{R_{\text {Penning,iz }}}{\sum_{i} R_{\mathrm{Ti}, \mathrm{iz}, i}}=\frac{n_{\mathrm{Ar}} k_{\mathrm{R} 6}}{n_{\mathrm{Ar}} k_{\mathrm{R} 6}+n_{\mathrm{e}} k_{\mathrm{R} 1}+n_{\mathrm{Ar}} k_{\mathrm{cx}}},
$$

TABLE II. The cases explored and numerical values of selected plasma parameters for argon discharge with a titanium target.

\begin{tabular}{lcccccccc}
\hline \hline Case & $\begin{array}{c}\mathrm{p} \\
(\mathrm{Pa})\end{array}$ & $\begin{array}{c}I_{\mathrm{D}, \text { peak }} \\
(\mathrm{A})\end{array}$ & $\begin{array}{c}t \\
(\mu \mathrm{s})\end{array}$ & $\begin{array}{c}T_{\mathrm{e}} \\
(\mathrm{eV})\end{array}$ & $\begin{array}{c}n_{\mathrm{e}} \\
\left(\mathrm{m}^{-3}\right)\end{array}$ & $\beta$ & $\begin{array}{c}\text { Stepwise } \\
(\%)\end{array}$ & $\begin{array}{c}\text { Penning } \\
(\%)\end{array}$ \\
\hline HiPIMS & 1.33 & 0.5 & 10 & 7.4 & $1.6 \times 10^{16}$ & 0.15 & 0.3 & 3.8 \\
HiPIMS & 1.33 & 0.5 & 150 & 6.7 & $1.5 \times 10^{17}$ & 0.15 & 9.9 & 12.1 \\
HiPIMS & 1.33 & 0.5 & 205 & 0.7 & $4.6 \times 10^{16}$ & 0.15 & 100 & 76.2 \\
HiPIMS & 1.33 & 40 & 10 & 5.7 & $3.4 \times 10^{17}$ & 0.4 & 5.1 & 2.5 \\
HiPIMS & 1.33 & 40 & 150 & 5.6 & $2.0 \times 10^{18}$ & 0.4 & 14.8 & 0.5 \\
HiPIMS & 1.33 & 40 & 205 & 1.5 & $4.1 \times 10^{17}$ & 0.4 & 99 & 37.7 \\
HiPIMS & 1.33 & 70 & 10 & 5.9 & $6.3 \times 10^{17}$ & 0.51 & 6.5 & 1.8 \\
HiPIMS & 1.33 & 70 & 150 & 4.3 & $1.0 \times 10^{18}$ & 0.51 & 15.4 & 0.9 \\
HiPIMS & 1.33 & 70 & 205 & 1.7 & $2.6 \times 10^{17}$ & 0.51 & 96.9 & 35.9 \\
\hline \hline
\end{tabular}
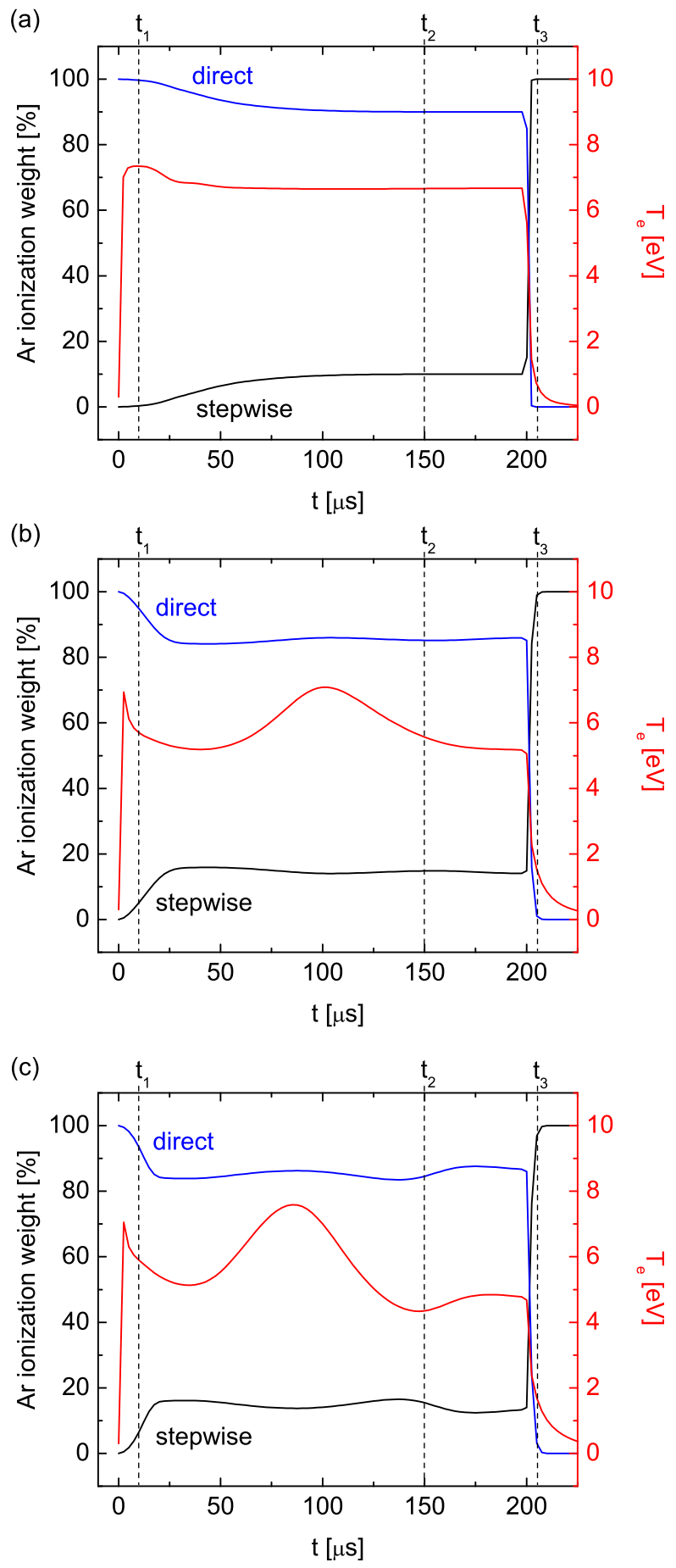

FIG. 3. The process weights of direct ionization and stepwise ionization of Ar via the metastable extracted from an m-IRM model run for a $200 \mu$ s long HiPIMS pulse at $1.33 \mathrm{~Pa}$, (a) $0.5 \mathrm{~A}$ peak current, (b) $40 \mathrm{~A}$ peak current, and (c) $70 \mathrm{~A}$ peak current. After pulse cutoff, the electron temperature and density drop rapidly. The direct ionization drops towards zero, and the high weight of the stepwise ionization at point $t_{3}$ shall be understood as a large fraction of an extremely small value.

where $n_{\mathrm{Ar}^{+}}$is the argon ion density and $k_{\mathrm{cx}}$ is the rate coefficient for charge exchange between $\mathrm{Ar}^{+}$and $\mathrm{Ti}$.

The ratios of Penning ionization for the HiPIMS discharges investigated are summarized in Table II. During the HiPIMS pulse (the $40 \mathrm{~A}$ and $70 \mathrm{~A}$ cases) they are very low, typically $R_{\text {Penning,iz }} / \sum_{i} R_{\mathrm{Ti}, \mathrm{iz}, i}<1 \%$ (and consequently is not shown). The reason for the low contribution of Penning ionization for HiPIMS is the much higher plasma density, the 


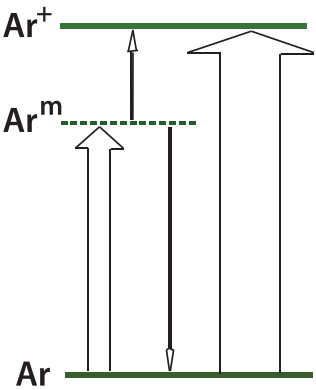

(a)

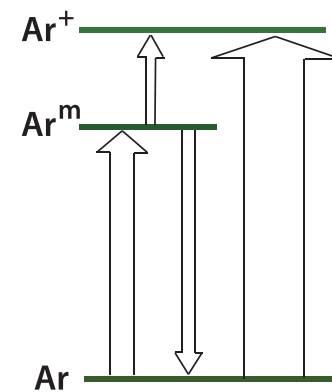

(b)
FIG. 4. A flow chart illustration of the two main ionization paths of argon where the widths of the arrows are proportional to the reaction rates extracted from the model for the $40 \mathrm{~A}$ peak current case. The ionization paths for HiPIMS discharge (a) at the time $t_{1}$ in Fig. 3, in the rising flank of the current, and (b) at equilibrium, time $t_{2}$ in Fig. 3. At $t_{1}$ (a), the $\mathrm{Ar}^{\mathrm{m}}$ level population is far below the equilibrium value which is indicated by a dashed line and stepwise ionization is negligible. Hence, only a small fraction of the ionization is stepwise. At equilibrium (b) the fraction of ionization that is stepwise is larger, but still small.

peak electron density $\left(2.1 \times 10^{19} \mathrm{~m}^{-3}\right.$ at $70 \mathrm{~A}$ peak current $)$ is roughly two orders of magnitude higher than for the $0.5 \mathrm{~A}$ case $\left(1.5 \times 10^{17} \mathrm{~m}^{-3}\right)$. This density enters the denominator of Eq. (5). This agrees with the findings of Britun et al. ${ }^{13,14}$ which by comparing the temporal behavior of the various species in an argon discharge with titanium target conclude that Penning ionization is negligible in the HiPIMS discharges. It is clear from Eq. (5), given that $k_{\mathrm{cx}} n_{\mathrm{Ar}^{+}} \ll k_{\mathrm{R} 6} n_{\mathrm{Ar}^{\mathrm{m}}}$, that in the limit of low $n_{\mathrm{e}}$, Penning ionization can become the dominant ionization route for the sputtered species. For $0.5 \mathrm{~A}$ peak current, the electron density at equilibrium ( $150 \mu$ s into the pulse) is $1.5 \times 10^{17} \mathrm{~m}^{-3}$ and Penning ionization has about $12 \%$ contribution. This is consistent with early findings in rf-sputtering glow discharges ${ }^{22,23}$ and with the global model calculation of Hopwood and Qian, ${ }^{24}$ for a magnetron sputtering discharge with a secondary inductively coupled discharge. Hopwood and Qian ${ }^{24}$ stated that for low electron density $\left(\ll 10^{17} \mathrm{~m}^{-3}\right)$, Penning ionization is the dominant ionization path and for high electron densities $\left(\gg 10^{17} \mathrm{~m}^{-3}\right)$, electron impact ionization plays the dominant role in ionization of the sputtered vapor. Sometimes the HiPIMS discharge is operated in the preionized mode. Then a low voltage is maintained between the high power pulses. Such an arrangement of an argon discharge with aluminum target was explored by Vitelaru et al..$^{25}$ who found that the steady state metastable density between the high power pulses is up to $10 \%$ of the maximum metastable density in the pulse. The same order of magnitude was found independently by Britun et al. ${ }^{14}$ however without pre-ionization. Thus, we made a separate test of the $0.5 \mathrm{~A}$ and $40 \mathrm{~A}$ cases with seed densities lying from $0.1 \%$ to $10 \%$ of the maximum argon metastable density. The presence of metastables before the high voltage pulse application only helps to reach the maximum value faster, compressing the period $t_{1}$ described by Stancu et al. ${ }^{9}$ but it does not affect the absolute value of the maximum. Therefore, these seed metastable densities lead to negligible changes, particularly on the direct versus stepwise ionization, and only a very small change in $T_{\mathrm{e}}(<3 \%)$, and all the other densities remain essentially the same. Thus, the results are robust against the changes in the initial metastable density.
The fractional ionization of the sputtered vapor is given by $n_{\mathrm{M}^{+}} /\left(n_{\mathrm{M}^{+}}+n_{\mathrm{M}}\right)$, where $n_{\mathrm{M}^{+}}$is the density of the ions of the sputtered vapor (metal) and $n_{\mathrm{M}}$ is the density of the neutral sputtered vapor. For the $0.5 \mathrm{~A}$ peak current, the ionization fraction for titanium is low, reaches roughly $3 \%$ towards the end of the pulse as seen in Figure 5(a). This ionization fraction is similar to what has been reported for the $\left[\mathrm{Ti}^{+}\right] /[\mathrm{Ti}]$ density
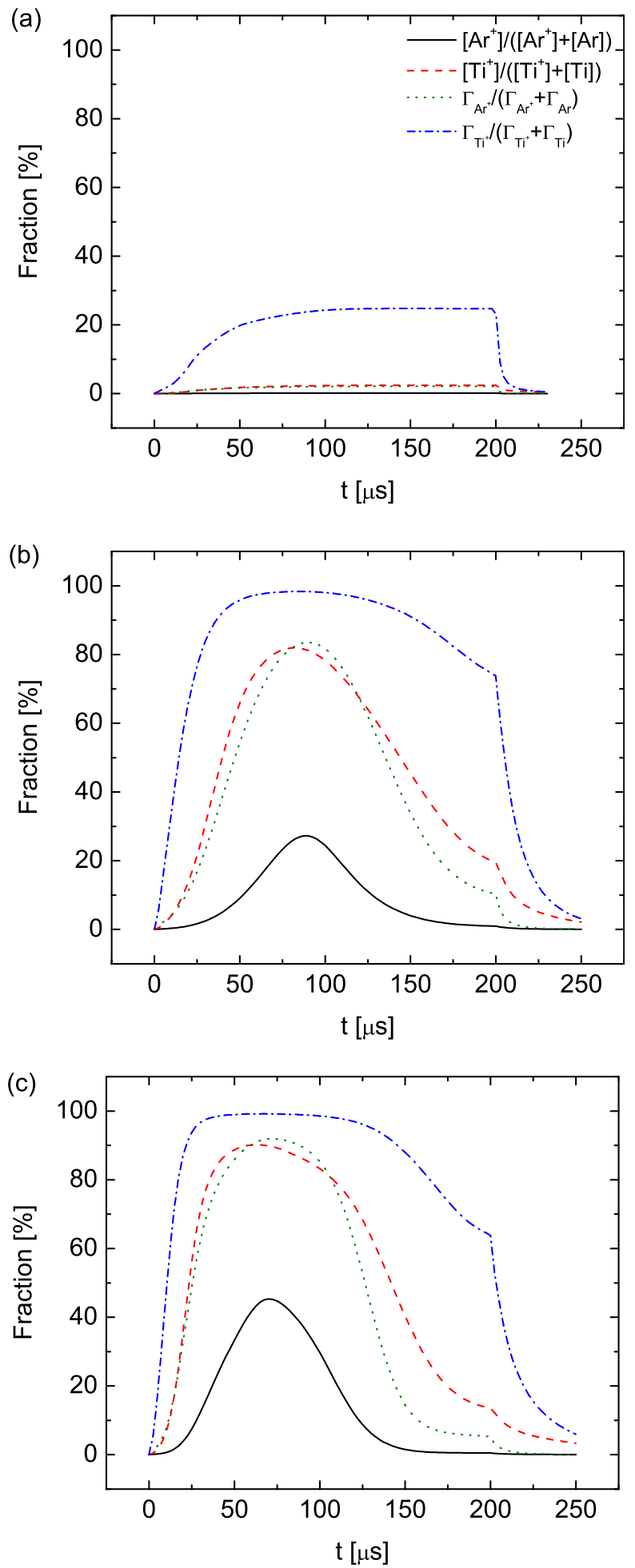

FIG. 5. The ionization fraction and ionized flux fraction for argon and titanium as a function of time for (a) $0.5 \mathrm{~A}$ peak current, (b) $40 \mathrm{~A}$ peak current, and (c) $70 \mathrm{~A}$ peak current, for a $200 \mu$ s long HiPIMS pulse at $1.33 \mathrm{~Pa}$. 
ratios in the dcMS discharge where for pressures below $6.67 \mathrm{~Pa}\left[\mathrm{Ti}^{+}\right] /[\mathrm{Ti}]<2 \% .^{26}$ Furthermore, it is found that the $\left[\mathrm{Ti}^{+}\right] /[\mathrm{Ti}]$ density ratio increases with increased distance from the target and increased discharge pressure and the $\left[\mathrm{Ti}^{+}\right] /[\mathrm{Ti}]$ density ratio is higher for an argon discharge than for a krypton or a xenon discharge. ${ }^{27}$ Also, Nafarizal et al. ${ }^{26,27}$ concluded that Penning ionization cannot be the dominant mechanism for ionization of titanium in dcMS. For the higher peak current, the metal ionization fraction is high and peaks at $81.7 \% 80 \mu$ s into the pulse and is $45 \%$ at $150 \mu$ s into the pulse for $40 \mathrm{~A}$ peak current but reaches $89 \% 62 \mu \mathrm{s}$ into the pulse for $70 \mathrm{~A}$ peak current as seen in Figures 5(b) and 5(c), respectively. This is somewhat lower ionization fraction than that reported by Bohlmark et al. ${ }^{20}$ or about $80 \%-90 \%$ for a $100 \mu \mathrm{s}$ long pulse with repetition frequency of $50 \mathrm{~Hz}$, pulse energy in the range of $2-12 \mathrm{~J}$ (average power $100-600 \mathrm{~W}$ ) and $1.33 \mathrm{~Pa}$ argon pressure, using optical emission spectroscopy, a line of sight averaged method. Britun et al. ${ }^{13}$ measured the temporal evolution of the absolute $\mathrm{Ti}$ and $\mathrm{Ti}^{+}$densities for a $20 \mu$ s long pulse at $1 \mathrm{kHz}$ (supplied energy per pulse $0.26 \mathrm{~J}$ ) and at pressure of $2.7 \mathrm{~Pa}$. They found that the ionization fraction is difficult to determine during the pulse on time but state that it reaches $40 \%$ in the off time. Note that these short pulses only capture the initial stages of the pulse, the current rise phase. This value agrees well with the ionization fraction for the 40 and $70 \mathrm{~A}$ cases which reaches roughly $40 \% 20 \mu$ s into the pulse as seen in Figures 5(b) and 5(c), respectively.

The metal ion flux fraction is defined as $\Gamma_{\mathrm{i}} /\left(\Gamma_{\mathrm{i}}+\Gamma_{\mathrm{n}}\right)$ where the ion flux to the substrate scales as $\Gamma_{\mathrm{i}} \sim \sqrt{T_{\mathrm{e}}}$ and the neutral flux scales as $\Gamma_{\mathrm{n}} \sim \sqrt{T_{\mathrm{g}}}$. It is important to note that in a weakly ionized discharge $T_{\mathrm{e}} \gg T_{\mathrm{g}}$ so that the metal ion flux fraction is larger than the fraction of ionized metal in the plasma. Thus, it is not necessary to completely ionize the sputtered metal to create a highly ionized flux to the substrate. ${ }^{28}$ This can be seen in Figure 5 where the ionized flux fraction is significantly higher than the ionization fraction for both $\mathrm{Ti}^{+}$and $\mathrm{Ar}^{+}$-ions. For the $0.5 \mathrm{~A}$ peak current, the ionized flux fraction for $\mathrm{Ti}^{+}$peaks at about $23 \%$ towards the end of the pulse. The time averaged ionized flux fraction for $\mathrm{Ti}^{+}$over $250 \mu \mathrm{s}$ is $18 \%$ for $0.5 \mathrm{~A}$ peak current, $71 \%$ for $40 \mathrm{~A}$ peak current, and $72 \%$ for $70 \mathrm{~A}$ peak current. The time averaged ionized flux fraction for $\mathrm{Ar}^{+}$over $250 \mu$ s is much lower or $1.5 \%$ for $0.5 \mathrm{~A}$ peak current, $35 \%$ for $40 \mathrm{~A}$ peak current, and $38 \%$ for $70 \mathrm{~A}$ peak current. Lundin et al. ${ }^{16}$ used a gridless ion meter to determine the ionized flux fractions of the sputtered material. They found the ionized flux fraction for titanium to be $60 \%$ for $2.0 \mathrm{~A} / \mathrm{cm}^{2}$ current density and increases with increasing current density but decreases slightly with increasing the pressure in the range of $0.5-2.0 \mathrm{~Pa}^{16,19}$ For current density of $1.0 \mathrm{~A} / \mathrm{cm}^{2}$, the ionized flux fraction is in the range of $41 \%-49 \%$. Poolcharuansin et al. ${ }^{18}$ reported ionized metal flux fraction in the range of $30 \%-50 \%$ and decreasing with increasing average power of $300-1300$ W. Kudlácek et al. ${ }^{17}$ reported that argon ions are the predominant ions in the total ion flux. They found that the ionization flux fraction of titanium is in the range of $60 \%-99 \%$ at $0.5 \mathrm{~Pa}$, average pulse current of $60 \mathrm{~A}$, and $200 \mu$ s long pulse at $1 \mathrm{kHz}$. Note that these measured values are time averaged values and are mostly somewhat lower than that predicted by m-IRM.

Figure 6 shows the temporal variations of the densities of the various species included in the model. For the $0.5 \mathrm{~A}$ peak current case, there is a small gas rarefaction, at most $6 \%$ at $200 \mu$ s into the pulse, as seen in Fig. 6(a). However, we see that there is a much more significant drop in the neutral argon density due to gas rarefaction and ionization for
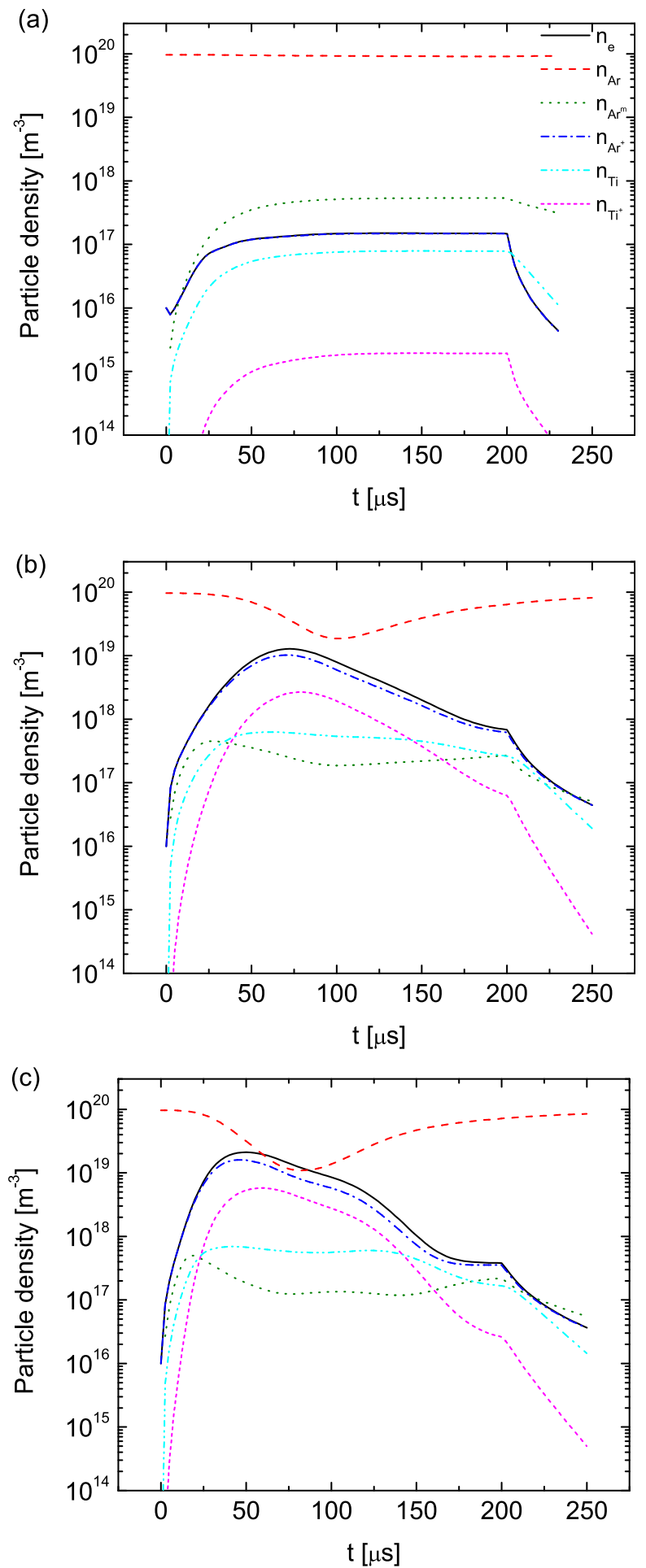

FIG. 6. The densities of the various species included in the model as a function of time for (a) $0.5 \mathrm{~A}$ peak current, (b) $40 \mathrm{~A}$ peak current, and (c) $70 \mathrm{~A}$ peak current, for a $200 \mu$ s long HiPIMS pulse at $1.33 \mathrm{~Pa}$. 
the higher peak currents 40 and $70 \mathrm{~A}$ as seen in Figs. 6(b) and 6(c), respectively. The drop in neutral argon density is $80 \%$ at $40 \mathrm{~A}$, and the minimum in the neutral argon density occurs $102 \mu$ s into the pulse. For the $70 \mathrm{~A}$ case, the drop in pressure is $89 \%$ and it occurs $85 \mu$ s into the pulse. Vlček et al. ${ }^{29}$ used optical emission spectrometry that encountered almost an order of magnitude decrease in the density of atomic argon but slightly less dramatic decrease in the density of argon ions roughly $50-70 \mu$ s into a $200 \mu$ s long pulse of $50 \mathrm{~A}$ average current during the pulse, while sputtering a $\mathrm{Cu}$ target. There is also a similar drop in the $\mathrm{Ar}^{\mathrm{m}}$ density which is discussed in detail elsewhere. ${ }^{9,10}$ The density of neutral titanium atoms and $\mathrm{Ti}^{+}$-ions reaches the values in the range of few times $10^{17} \mathrm{~m}^{-3}$ and agrees well with the measurements of Britun et al. ${ }^{13}$ but with $20 \mu$ s long pulses at $1 \mathrm{kHz}$ (supplied energy per pulse $0.26 \mathrm{~J}$ ) at $2.6 \mathrm{~Pa}$. For the $40 \mathrm{~A}$ peak current, the argon ion density peaks roughly $70 \mu$ s into the pulse and the $\mathrm{Ti}^{+}$-density peaks a few $\mu \mathrm{s}$ later. We note that for the $0.5 \mathrm{~A}$ peak current the $\mathrm{Ar}^{\mathrm{m}}$ density is higher than the electron density while at $40 \mathrm{~A}$ peak current the electron density and the $\mathrm{Ar}^{+}$-ion density are significantly higher than the $\mathrm{Ar}^{\mathrm{m}}$ density. The $\mathrm{Ti}^{+}$-ion density is always lower than the $\mathrm{Ar}^{+}$-ion density. Lundin et al. ${ }^{16}$ reported that the electron density in the range of 2-40 $\times 10^{17} \mathrm{~m}^{-3}$ and electron temperature in the range of $2.9-4.1 \mathrm{eV}$ for pressure $0.5-2.0 \mathrm{~Pa}$ at $4 \mathrm{~cm}$ from the target, which is somewhat lower than that reported by Bohlmark et al. ${ }^{15}$ or few times $10^{19} \mathrm{~m}^{-3}$ next to the target $(2 \mathrm{~cm})$ at $2.66 \mathrm{~Pa}$. The model gives somewhat higher values for the peak electron density as the IR is closer to the target than is allowed to measure using a Langmuir probe. Also, as these calculations are based on the volume averaged densities it should be kept in mind that there is certainly a strong spatial variation in the species densities as has been demonstrated by Langmuir probe measurements ${ }^{15}$ and by LIF measurements. ${ }^{14}$ The latter measurements show that the ions are localized in the race track vicinity while the neutrals are mainly located in the target center. This translates also onto the metastable density. Thus, we would expect spatial variation in the role of the argon metastables with regard to stepwise ionization and Penning ionization. Also, as we move away from the target there is a decrease in the electron density and electron temperature, so the role of stepwise ionization and Penning ionization may vary from what we observe here for the IR. Under the conditions of low electron density $\left(n_{\mathrm{e}} \ll 10^{17} \mathrm{~m}^{-3}\right.$ ), Penning ionization is found to be the dominant ionization path ${ }^{24}$ and is consistent with the accepted ionization mechanism for conventional diode sputtering. When high electron densities are generated, however, electron impact ionization plays a significant role. In our case, we clearly see that Penning ionization becomes more important in the $0.5 \mathrm{~A}$ case. A similar situation with a lower plasma density applies in the bulk plasma and will likely generate similar results.

\section{CONCLUSION}

In diode sputtering and dcMS, Penning ionization can be an important ionization mechanism for the sputtered species but the degree of ionization is small. In HiPIMS, the sputtered species ionization is high, up to $89 \%$ for the case of an argon discharge with a titanium target is investigated here. Penning ionization is always negligible. The main reason is the higher electron density, but also a higher electron temperature in the HiPIMS contributes. Stepwise ionization through the $\mathrm{Ar}^{\mathrm{m}}$ level is always negligible during the breakdown phase in the HiPIMS pulses, and plays a significant (but never dominating) role only later in the pulse. The model predicts a time averaged ionized flux fraction of roughly $70 \%$ for titanium, which is a slightly higher value than observed experimentally.

\section{ACKNOWLEDGMENTS}

J.T.G and N.B. gratefully acknowledge the hospitality of CNRS and University Paris-Sud, Orsay where most of this study was done. This work was partially supported by the Icelandic Research Fund Grant No. 130029-053, the Swedish Government Agency for Innovation Systems (VINNOVA) Contract No. 2014-04876, and the Belgian Government through the Pôle d'Attraction Interuniversitaire (PAI, P7/34, "Plasma surface interaction").

${ }^{1}$ J. T. Gudmundsson, N. Brenning, D. Lundin, and U. Helmersson, J. Vac. Sci. Technol., A 30, 030801 (2012).

${ }^{2}$ O. A. Malkin and A. V. Pyshnov, High Temp. 9, 802 (1972).

${ }^{3}$ P. M. Tyuryukanov, I. K. Fetisov, and A. D. Nikolsky, Sov. Phys.-Tech. Phys. 26, 1182 (1981).

${ }^{4}$ M. A. Raadu, I. Axnäs, J. T. Gudmundsson, C. Huo, and N. Brenning, Plasma Sources Sci. Technol. 20, 065007 (2011).

${ }^{5}$ C. Huo, M. A. Raadu, D. Lundin, J. T. Gudmundsson, A. Anders, and N. Brenning, Plasma Sources Sci. Technol. 21, 045004 (2012).

${ }^{6}$ N. Brenning, D. Lundin, M. A. Raadu, C. Huo, C. Vitelaru, G. D. Stancu, T. Minea, and U. Helmersson, Plasma Sources Sci. Technol. 21, 025005 (2012).

${ }^{7}$ C. Huo, D. Lundin, M. A. Raadu, A. Anders, J. T. Gudmundsson, and N. Brenning, Plasma Sources Sci. Technol. 22, 045005 (2013).

${ }^{8}$ C. Huo, D. Lundin, M. A. Raadu, A. Anders, J. T. Gudmundsson, and N. Brenning, Plasma Sources Sci. Technol. 23, 025017 (2014).

${ }^{9}$ G. D. Stancu, N. Brenning, C. Vitelaru, D. Lundin, and T. Minea, Plasma Sources Sci. Technol. 24, 045011 (2015).

${ }^{10}$ C. Vitelaru, D. Lundin, G. D. Stancu, N. Brenning, J. Bretagne, and T. Minea, Plasma Sources Sci. Technol. 21, 025010 (2012).

${ }^{11}$ A. A. Kudryavtsev and V. N. Skrebov, Sov. Phys.-Tech. Phys. 28, 30 (1983).

${ }^{12}$ D. V. Mozgrin, Ph.D. thesis, Moscow Engineering Physics Institute (MEPhI), 1994 (in Russian).

${ }^{13}$ N. Britun, M. Palmucci, S. Konstantinidis, and R. Snyders, J. Appl. Phys. 117, 163303 (2015).

${ }^{14}$ N. Britun, M. Palmucci, S. Konstantinidis, and R. Snyders, J. Appl. Phys. 117, 163302 (2015)

${ }^{15}$ J. Bohlmark, J. T. Gudmundsson, J. Alami, M. Lattemann, and U. Helmersson, IEEE Trans. Plasma Sci. 33, 346 (2005).

${ }^{16}$ D. Lundin, M. Čada, and Z. Hubička, Plasma Sources Sci. Technol. 24, 035018 (2015)

${ }^{17}$ P. Kudlácek, J. Vlcek, K. Burcalová, and J. Lukás, Plasma Sources Sci. Technol. 17, 025010 (2008).

${ }^{18}$ P. Poolcharuansin, M. Bowes, T. J. Petty, and J. W. Bradley, J. Phys. D: Appl. Phys. 45, 322001 (2012).

${ }^{19}$ T. Kubart, M. Čada, D. Lundin, and Z. Hubička, Surf. Coat. Technol. 238, 152 (2014).

${ }^{20}$ J. Bohlmark, J. Alami, C. Christou, A. P. Ehiasarian, and U. Helmersson, J. Vac. Sci. Technol., A 23, 18 (2005).

${ }^{21}$ T. M. Minea, C. Costin, A. Revel, D. Lundin, and L. Caillault, Surf. Coat. Technol. 255, 52 (2014). 
${ }^{22}$ J. W. Coburn and E. Kay, Appl. Phys. Lett. 18, 435 (1971).

${ }^{23}$ E. W. Eckstein, J. W. Coburn, and E. Kay, Int. J. Mass Spectrom. Ion Phys. 17, 129 (1975).

${ }^{24}$ J. Hopwood and F. Qian, J. Appl. Phys. 78, 758 (1995).

${ }^{25}$ C. Vitelaru, T. Minea, L. de Poucques, M. Ganciu, and G. Popa, Rom. J. Phys. 56, 47 (2011).
${ }^{26}$ N. Nafarizal, N. Takada, K. Shibagaki, K. Nakamura, Y. Sago, and K. Sasaki, Jpn. J. Appl. Phys., Part 2 44, L737 (2005).

${ }^{27}$ N. Nafarizal, N. Takada, and K. Sasaki, Jpn. J. Appl. Phys., Part 148 , 126003 (2009).

${ }^{28}$ J. Hopwood, Phys. Plasmas 5, 1624 (1998).

${ }^{29}$ J. Vlček, A. D. Pajdarová, and J. Musil, Contrib. Plasma Phys. 44, 426 (2004). 